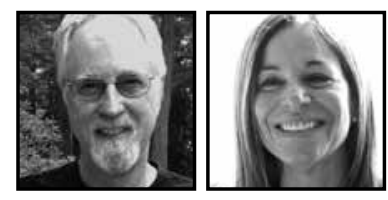

\title{
Wondering With Children: The Importance of Observation in Early Education
}

\author{
George Forman and Ellen Hall, Videatives, Inc. \\ Amherst, Massachusetts
}

From "Wondering With Children: The Importance of Observation in Early Education," by George Forman and Ellen Hall, 2005, Early Childhood Research \& Practice, Volume 7 Number 2. Copyright 2005 by George Forman and Ellen Hall. Reprinted with permission.

\section{ABSTRACT}

This paper asserts that through the process of observation, documentation, and interpretation of children's goals, strategies, and theories, teachers gain insight into children's thinking. As a result of this process, teachers are better able to engage children in conversations and investigations that have the potential to extend their learning in both depth and breadth. Utilizing brief video clips of both children and adults to support its premise, the paper outlines and discusses relevant aspects of observation for understanding and introduces the concept of the videative as a powerful resource for revisiting and analyzing documented observations.

\section{Introduction}



hildren are sometimes spontaneous, sometimes reserved; joyful now, sad later; friendly and reserved; competent and naïve; talkative and quiet. To be childlike is to experience an almost unpredictable array of discoveries, emotions, and levels of energy. Children are unique and complex and thus often difficult to comprehend. And they do not readily engage us in dialogue in order to explain the reasons for their caprice as they explore the world that surrounds them. Yet, as teachers, it is important for us to know our children deeply, to flow with their currents, and to extend their nascent theories about how the world works. 
Given the delightful yet often enigmatic characteristics of young children, we learned decades ago that in order to comprehend children we must begin by observing them as they play. But what do we see as we observe, and how do we use our observations to enhance our effectiveness as teachers?

\section{Five Reasons to Observe Children}

Here are some of the reasons that teachers offer when asked about the value of watching and listening to children:

- If I watch the children play, I can discover their interests.

- By observing children, I can assess their developmental levels.

- I look to see what strategies children use to attain their goals.

- Observing children helps me know what skills the children need to practice.

- When I observe children at play, I learn a lot about their personalities.

We want to use these reasons again, so we will provide an example that illustrates the general meaning of each:

- Interests-He loves to play with trucks.

- Developmental level-She throws the ball either very hard or not at all, but she does not vary the throw along a continuum of very hard, hard, and soft.

- Strategies-She tries to influence her friend's actions by controlling all of the crayons.

- Skills-She has trouble stringing beads onto a knotted shoestring.

- Personality-She is reserved and does not like to take risks.

In essence, we can learn at least five attributes of our children when we observe them closely:

- Their interests and preferences

- Their levels of cognitive and social development

- Their strategies for creating desired effects

- Their skills and accomplishments

- Their personalities and temperaments 
Each of the preceding objectives for observing is relevant if we desire to learn about children and thus improve the quality of our teaching. But we think that one of these objectives is best suited for gathering information in order to engage in high-level conversations with young children about their theories and attitudes, conversations that can support and extend their learning in both depth and breadth.

If we truly want to have high-level conversations with children about their beliefs, expectations, and assumptions about how something works or why something occurs, what do we need to know about the children? Quite simply, we need to know their beliefs, assumptions, and expectations so that we might enter the conversation with a paraphrase or counterpoint:

- Knowing children's interests might help us prepare the environment, but it does not help us have better conversations.

- Knowing children's skills might help us think about games to play that might encourage them to practice their skills, but it does not help us have better conversations.

- Knowing children's developmental level might help us predict what questions the children can answer, but it does not help us enter into a meaningful conversation with the children.

- Knowing something about a child's personality might help us be sensitive about our tone of voice or help us know what topics to avoid, but it does not help us have better conversations.

In order to have a meaningful conversation with a child, we need to know what the child thinks can be done in real situations (possible goals), and we need to know the procedures that the child believes will make things happen (possible strategies). If we have watched and listened long enough to determine the child's goals and his strategies for attaining those goals, then we have both a resource for understanding the child and an interesting basis for a high-level conversation.

We might say, "It seems like you think the ball will roll faster if you make the incline steeper." Or we might say, "Do you think you will have more friends if you have crayons?" But then in revisiting an experience with a child, putting that experience into words, we need to go beyond the observed strategies and consider the theories that make those strategies reasonable. 
Considering children's theories requires more than a careful transcription of what they say and do. We have to dig. We have to abstract the meaning of elliptical sentences, aborted movements, or a confusing explanation, request, or description. Children are competent learners, but as teachers, we have to slow down, carefully observe, and study our documented observations in order to understand the ideas that they are attempting to convey. In addition to slowing down, observing, and studying children's actions and narration, understanding children's theories requires a general knowledge of child development and a willingness to speculate.

In the pages that follow, you will view several video clips of children engaged in play. Observe the children in these clips carefully. Then read our speculations on what the children may be thinking (possible theories) and our ideas about what we might say to the children on another day as we revisit the experience that we have observed.

\section{Goals, Strategies, and Theories}

As we observe children, we need to consider their goals. What effects are they trying to create? We observe their actions and listen to their comments to determine the strategies they choose to attain those goals. The relation between the strategy and the goal will reveal a possible theory, a theory about how to make the desired effect occur. The theory, correct or incorrect in an objective sense, makes the child's choice of strategy sensible. The theory comes from us. It is our speculation. It is our attempt to find an entry into the child's world. All high-level conversations begin with someone speculating about the meaning of the other person's words or actions.

Watch this 2-year-old boy named Toby, who is trying to hit a large ball with a golf club. Observe not only what he does but also think about what he does not do (view video, 1.3 MB). [The video files in this article require QuickTime for viewing. The files take a minute or two to load after clicking on the link. Readers can download the free QuickTime player.]

Toby's goal is to move the ball across the grass. To accomplish this goal, the strategy he chooses is first to make contact with the ball by placing the head of his golf club on the ball's side and then to push the ball forward, using a shoveling action. He does not move the club back away from the ball and then swing the club swiftly forward. Let's watch this video clip again (1.3 MB). 
We could say that Toby needs to develop his ability to hit the ball and encourage him to try again. We might show him how to draw his golf club back before he makes contact with the ball. But what if instead we try to determine why Toby hits the ball in this way. What theory does he hold that makes his strategy reasonable to him?

We can speculate that Toby is thinking, "Why would I draw the golf club backward if I want to make the ball go forward? It is reasonable to place my golf club on the ball and shovel it forward because I know that the club has to make contact with the ball in order for it to move. So, I place the club in contact with the ball and push it ahead."

What implications does this approach to observation have for our conversations with young children? Instead of showing Toby how to hit the ball correctly, we can address Toby's thinking. We might say, "You pressed your club against the ball and shoveled it forward." We deliberately choose to use the verbs, "pressed" and "shoveled" in order to encourage Toby to reflect on his strategies, the procedure he selected to reach his goal. In time, the child will comprehend the meaning of the verbs that describe his actions and will learn to reflect on those actions. And eventually his ability to reflect will help him "repair" his misunderstandings or theories about how things work or how to make a desired effect occur.

If one strategic action made by a child can reveal an implied theory, then a set of related actions can prove even more helpful in comprehending and conversing with children. The following video clips show Jack, a 4-year-old boy, playing at the water flume at Boulder Journey School in Colorado. The flume is about 40 feet long; there is a gentle flow of water coming from the high end, and sand has been spread along the floor. Jack is attempting to get his lightweight ball to roll or float from the high end to the lower end of the flume.

Notice the varied strategies that Jack uses to attain his goal. Sometimes he releases the ball, sometimes he tosses it, sometimes he slaps it, and sometimes he raises and carries it through the air to a spot further down. Why does Jack make these adjustments? What are his theories about the ways in which the ball will interact with the changing nature of the flume's floor? Click on the links in the paragraph below to view Jack's strategies and think about his possible theories.

We can consider each of Jack's selected adjustments individually and speculate on the theory that makes each adjustment reasonable. Jack begins by lifting the ball (view video, 0.4 MB) over the wet sand, then dropping it a slight distance down the flume. But this is not interesting because it doesn't make use of the flume's incline. 
So Jack places the ball on the smooth, inclined surface of the flume floor and releases the ball (view video, $0.2 \mathrm{MB}$ ) with open fingers. He seems to understand that because the surface contains no sand, it is smooth enough to allow the ball to roll on its own. When the ball encounters the water, Jack slaps the ball (view video, $0.3 \mathrm{MB}$ ), as though he knows that it is stuck but not completely immobile. Then when the ball comes to a raised area, a hump in the flume, Jack determines that a lift, a release, or a slap will not work. He raises the ball and airlifts (view video, $2.1 \mathrm{MB}$ ) it over the hump, making noises like an airplane as he walks downstream. Clearly Jack holds several sophisticated theories about how things work, illustrated by his strategies. Watch again.

\section{Lifts | Releases | Slaps | Raises}

How can we use our understanding of Jack's thinking to engage him in a high-level conversation? Perhaps we have captured Jack playing with the ball in the water flume on video. We might sit with Jack, revisit the video, and reflect on his actions. We can say, "That time instead of releasing the ball, you slapped it." By creating a narrative that puts Jack's selected adjustments into words, we are supporting and encouraging him to not only think about his strategies but also to think about the associated theories.

Observing children provides us with a key that allows us to enter their wonderment. Once inside, we must not be afraid to speculate on what they might be thinking. Our theory about a child's theory must be evident in our comments or questions. So rather than ask the child a general question, "Why did you do it that way?", we might instead make a specific comment based on our observations and say, "That time you had to toss it. Before you were able to just let it go." If our speculations are inaccurate, the child will let us know by either correcting our misconceptions or ignoring our remarks. On the other hand, if our speculations are accurate, they should serve to bring the child's theories into consciousness, and we can anticipate that we will receive an explanation from the child.

\section{Knowing What Someone Knows}

The following video clips focus on a 4-year-old girl, Avery, who is trying to get her large and loveable dog, Jasmine, to lie all the way down on the bed that Avery has made. Avery is successful in getting Jasmine to place her body on the bed, but she is not able to coax Jasmine to put her head down. Avery wants Jasmine's head down. To accomplish her goal, she makes a pillow. This strategy appears reasonable. The pillow 
gives Jasmine a spatial clue for what to do. Avery adds a blanket, another cue for sleeping, then pats Jasmine's head rather hard, almost as if Jasmine just needs to be encouraged. Watch this clip (7.1 MB).

\section{View transcript of video | View both video clip and transcript at the same time}

When these strategies don't work, Avery decides to give Jasmine a treat. Perhaps she remembers that one can train a dog to do tricks using a treat in some way. But then Avery gives Jasmine her treat before she accomplishes her task. What might Avery be thinking? Why does she choose this strategy? What theory makes the strategy reasonable to her? Watch this clip (3.3 MB).

\section{View transcript of video | View both video clip and transcript at the same time}

Perhaps Avery is thinking, "If I am kind to Jasmine, then Jasmine will do what I ask." This theory makes sense on one level, but if we go deeper, we realize that the theory assumes that Jasmine will understand that after she is given a treat she must comply with the stated request. It also assumes that Jasmine knows what Avery wants her (the dog) to do.

Our theory about Avery's theory provides a beginning point for revisiting the experience with her. We can encourage her to make her thinking more explicit by saying, "Jasmine likes the cracker, but does she know what you want her to do?"

\section{Observing Children for Understanding}

\section{Review the Research on Child Development, Including Children's Milestones and Misconceptions}

While observing the video of Avery and her dog, Jasmine, we must think about the research surrounding children's theory of mind (Leslie, 1987). Theory of mind concerns the child's need to take the perspective of another in order to communicate effectively. In this scenario, Avery's theory of the dog's mind includes the notion that "she knows what I am thinking." Child development research also holds that preschool-age children tend to blame the listener when communication fails rather than revise their message (Girbau, 2001; Glucksberg, Krauss, \& Weisberg, 1966). The child may think, "You are not listening" instead of, "My message needs to be more explicit." A general knowledge 
of child development, including research on theory of mind might lead us to comment, "Maybe Jasmine only understands dog language."

To see a more complete analysis of Avery's interaction with Jasmine, view this more extensive set of videos (HTML page and QuickTime files; may take a minute or two to load).

\section{Review Classic and Contemporary Research on Knowledge Domains}

Although it is important to review the significant research in child development, some types of research are more helpful for teachers. Research about broadly defined concepts, such as class inclusion and transitivity, probably will not help us interpret the relevant details of an ordinary moment or have a constructive conversation with a child. Children are curious about events and phenomena, such as why the hamster died and where shadows come from. To connect with their curiosity, it is essential to know what the research says about children's understanding of knowledge domains, such as death and shadows.

Research moves us beyond treating knowledge domains as topics that are no more than lists of facts. Research helps us understand why some aspects of a domain are easy to understand and other aspects are more complex. For example, constructivist educator Rheta DeVries conducted a study on the development of children's understanding of shadows. She found that to understand shadows as a cause-and-effect system, children had to understand that a shadow is not the projection of a black light but rather is the absence of light when light, person, and wall are placed in a special relation. This study is described in DeVries (1986).

Look for research on familiar domains of knowledge or familiar problem-solving domains, such as block play, jigsaw puzzles, board games (DeVries \& Fernie, 1990), pretend play scripts, early number concepts (Gelman \& Gallistel, 1978), friendship, illness (Kalish, 1996), money (Furth, 1980), family resemblance (Springer, 1992), morality (Coles, 1997), and so forth. Be particularly alert for research that helps you understand the characteristics that make one domain different from other domains and the stages in learning that domain. You can find a good summary of domain knowledge in Wellman and Gelman (1997). For a set of video clips that are arranged around problem-solving domains download this list from Videatives, Inc. 


\section{Review Documented Observations Many Times}

Subtle but important details will reveal themselves as we review and analyze our notes and video clips.

Often we do not notice the cleverness of a child's work until we view a video clip several times, as in the case of Kieran, a 3-year-old boy who is gluing plastic caps and felt buttons onto a wooden board. Watch the first part of this video of Kieran's work by clicking here (17.0 MB).

When the first author first viewed this videotape, he found it rather uninteresting, a child engaged in a relatively routine gluing activity. Then, after reviewing the tape three times, he noticed that Kieran was improving the efficiency of the strategy that he was using to make a symmetrical pattern, removing unnecessary steps. For example, instead of dabbing glue in one spot and placing an item on the glue, Kieran began to place extra glue on his spatula so that he could dab two spots of glue on the board before he placed items on either spot, thus eliminating a trip to the glue dish. Watch this animated graphic that shows how Kieran eliminated steps (0.9 MB).

An activity that at first viewing appeared mundane turned out to be a profound example of self-regulated learning or what Piaget called the schematization of actions. The separate acts of "getting glue to dab" were schematized, that is, Kieran began to see the "form" of the sequence. He might have been thinking, "First I get glue to dab for one item from the junk bin, and then I return a second time to get more glue to dab for a matching item from the junk bin." Once Kieran begins to think at this level of abstraction-first, more, second - he is able to reason, "If I am always going to place a second dab of glue for a matching item from the junk bin, I might as well get enough glue for two dabs on the wooden board."

To see a more complete analysis of Kieran's play, view this more extensive set of videos (HTML page and QuickTime files; may take a minute or two to load).

\section{Look for Laughter-Which Often Means That an Expectation or Theory Has Been Violated}

Laughter can come from the children or the teachers; both are relevant to our understanding. In the video of Victoria, we observe her pretending to dish mashed potatoes onto her teacher's plate. With great skill, she pretends to scoop the potatoes with her spoon and then empties the potato-filled spoon in a space not occupied by baked potato or cucumber. When Victoria discovers a grape in the pan, she eats it with great 
relish. The teachers laugh. Why might the teachers laugh? Watch this brief video clip (11.6 MB).

\section{View transcript of video | View both video clip and transcript at the same time}

Perhaps the teachers laugh because Victoria has conveniently slipped out of the pretense mode to eat a real grape. It is as though she is saying, "Pretending is ok, but you don't need to pretend when you have a real grape to eat." This navigation in and out of a pretend frame is an essential aspect of children's play. As their play develops, children mark pretense as such by using phrases such as "Let's pretend." Then they proceed to negotiate a script together; a script that they act out.

\section{Look for the Aborted or Abbreviated Action-Which Often Means That the Child Has Changed Her Thinking or Is Thinking About What Strategy to Choose Next}

After viewing many video clips of children, patterns in the ways in which they approach problems begin to emerge. For example, if they are confident that their strategies will produce the desired effect, their actions flow uninterrupted. But as soon as they anticipate a problem, they pause and/or change directions. Pauses and changes in a child's actions provide us with a cue that the child has a thought that merits interpretation. Consider Kaylie, a 2-year-old child who is playing on the kitchen floor with plastic lids, containers, and measuring cups. For some time, she has been trying to place a blue lid on a clear container. At a certain point, Kaylie picks up a measuring cup and moves the blue lid to rest on its open end. However, the blue lid cannot rest on the measuring cup's rim because the open end of the cup is larger than the lid. Kaylie pauses. Then she lets the blue lid fall to the bottom of the cup and presses it down firmly. What does Kaylie's pause mean? Watch this brief video clip (1.4 MB).

Based on Kaylie's previous actions with the blue lid and the clear container, we can speculate that her goal is to make the lid fit on the measuring cup and that she holds the theory that the lid should fit on the top. That is why she pauses; she wants to find a way to make the lid come to rest on the top of the measuring cup. When her initial strategy doesn't yield the desired results, Kaylie theorizes that the lid might fit best on the bottom of the measuring cup. If the lid fits somewhere, then her goal of fitting the lid has been achieved. We understand that Kaylie is not interested in closing the container but rather in finding a place for the blue lid to comfortably rest. Watch this action again by clicking here. 
To see a more complete analysis of Kaylie's play, view this more extensive set of videos (HTML page and QuickTime files; may take a minute or two to load).

\section{Look for the Co-construction of Knowledge-Where Children Are Supporting or Extending Each Other's Work}

Children often collaborate with one another, performing different but complementary actions in order to attain a shared goal. One child adds a block to the top of a tower, while another child steadies the bottom. One child pokes a hole in a piece of clay knowing that her friend waits with a flower stem to insert in this hole. One child holds the end of the tablecloth firmly, while another child smoothes out the ruffles. Children may also extend one another's ideas. One child rolls a piece of clay and creates a snake. A second child does the same but then bends the snake, creating a closed circle. The first child is intrigued and does the same with his clay snake. Note that the second child required the first child's idea in order to create his extended idea, which the first child then adopts.

\section{Look for Examples of Representation-Where Children Are Inventing New Ways to Capture or Express Meaning}

Children can use representation as a forum for the co-construction of ideas. Two boys, Zachary and David, draw a map without much attention to scale. Nevertheless, their symbols capture interesting aspects of shape, location, boundary, and part-towhole relations. In the first moments of the video of this scenario, Zachary makes an "X" inside a circle and announces, "That's were I live." David extends Zachary's idea and indicates (off camera) a place on the map where his grandfather lives. David speculates about the distance between his grandfather's house and Boulder and ponders, "But my grandpa lives in lowa." To justify the discrepancy between actual distances and a map's scale, he explains in response to his teacher's question, "But it's a pretty big map." Watch this video clip (11.2 MB).

\section{View transcript of video | View both video clip and transcript at the same time}

In another segment of the map-making activity, David explains that he is drawing the trajectory of missiles, straight lines that are not connected to anything. Zachary adds qualifiers to these missile lines: swirling marks and "Xs." Zachary explains to the teacher that the swirling marks indicate that the missiles have exploded and the "Xs" indicate that the missiles have not exploded yet. Watch this video clip (15.5 MB). 


\section{View transcript of video | View both video clip and transcript at the same time}

By degrees, David and Zachary work together to improve the readability of their symbol system, thereby making it possible to make relevant comments about what the map "says." When children make their thoughts visible through representation, they are better able to have focused conversations with adults and peers. Indeed, representations also encourage children to reflect more carefully upon their own meanings and theories.

\section{Look for Examples of Meta-cognition- Where Children Are Thinking About Thinking}

We often hear a child say, "I am not very good at this" while attempting to draw something such as a face. This comment indicates that the child has evaluated his own ability. The child has done more than simply remember the last time he tried to draw a face. He also remembers his thoughts, his assessment of the quality of his drawing. The child is thus thinking about his thinking.

When we reflect on this comment with a child, we do not want to focus our attention on drawing skills. We want to focus on the child's thinking, the reasoning behind his evaluation of self. So we don't want to offer counter-examples of his drawing ability by saying, "Oh, I have seen you do this rather well." This statement might well end the conversation. On the other hand if we ask, "What is it about a face that is difficult to draw?", we potentially launch a dialogue with many possible twists and turns. We are encouraging the child to be more conscious of the details of his evaluation. In so doing, the child might well develop a drawing strategy that avoids, compensates for, or overcomes the difficulty that he has identified. If the child is too young to articulate his reasons for thinking that he is not good at drawing faces, we can summarize his thoughts by saying, "You remember doing this before and not liking the face you drew." This statement provides a more articulated expression of what the child most likely meant when he said, "I am not very good at this." Our descriptive summary orients the child to his thinking and creates a base from which he can begin to think about his thoughts.

Meta-cognition also refers to thinking about someone else's thinking. You observed one example of this when Avery tried to communicate her desire to Jasmine, her dog. Avery was thinking about Jasmine's thinking, assuming that Jasmine was not paying attention to her request. Once we develop a sense of the assumptions that children are making about their own thinking or someone else's thinking, we can engage them in highlevel conversations as we wonder along with them about the meaning of their world. 


\section{Define the Children's Theories at a More General Level}

Our speculation about what theory a child might hold, a theory that makes his chosen strategy reasonable, can inform subsequent conversations as we revisit similar experiences with other children. However, for our speculations to be useful with other children in new situations, they must be defined at a higher level of generality. Following are some examples of children's theories that came from an analysis of their comments. In the first set of examples, the theories are specific to one context. In the next section, they are defined at a higher level of generality. The more general definition can help us identify children's theories even when the context changes.

Specific theories:

- Since a worm has no legs, it moves by sliding on a surface.

- A shadow on the floor is like a spot of black paint than can be hidden with a blanket.

- A baby chick gets out of its shell by rolling the shell off the table.

- Air blows out of both ends of a floor fan.

- If the puzzle piece does not fit, I should discard it and try another.

- My friends will like me if I let them play with my toys.

- A party balloon floats up because the air inside pushes up on the top.

- If I cannot have a turn pushing the stroller, I will ask my friend to push me.

General theories (in italics). Note that several of the general definitions include a theory that the child does not hold. Thinking about the theory not held can help us determine the next possible developmental step in the learning progression:

- Since a worm has no legs, it moves by sliding on a surface. >> Things that are not elevated cannot move in discrete steps.

- A shadow on the floor is like a spot of black paint that can be hidden with a blanket. >> Even spots that move can be hidden with a cover-as opposed to, some moving spots indicate the absence of light.

- A baby chick gets out of its shell by rolling the shell off the table. >> Enclosing objects can be cracked through hard contact with outside surfaces-as opposed to, enclosing objects can be cracked from within. 
- Air blows out of both ends of a floor fan.

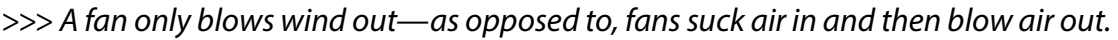

- If the puzzle piece does not fit, I should discard it and try another. >> Objects either work or do not work-as opposed to, an object can be modified if it does not work.

- My friends will like me if I let them play with my toys. >> What I give to my friends will always please them - as opposed to, my friends may not like or want what I give them.

- A party balloon floats up because the air inside pushes up on the top. >> Floating is caused by an upward push-as opposed to, the relative density of two mediums causes floating.

- If I cannot have a turn pushing the stroller, I will ask my friend to push me. >> If I cannot be the agent of the action, then I can be the recipient, which at least keeps me in the game.

\section{Conclusion: A Summary of Ways to Use Our Observations}

- Compose a list of possible goals, strategies, and theories revealed in your observational records (e.g., video clips).

- Choose the theories that are most reasonable given the children's experiences and most consistent with what you know about child development research.

- Discuss the ways in which the identified theories can be extended within and across various contexts.

- Find key segments in videos and revisit these segments with the children.

- During the video revisiting, focus on the children's thinking as well as their actions (click here to read about Instant Video Revisiting).

- Modify materials, make comments, and ask questions in ways that might provoke new perspectives on the identified theories and strategies.

- Encourage and support children in making their thinking visible to themselves for study and revision (e.g., drawing their faces, looking at their spoken words in print). 
- Give children the tools necessary to represent their theories and communicate them to others (e.g., presenting to a video camera, drawing maps and other graphics, adding comments to photographs of themselves at work).

Digital video allows us to observe and document children's explorations and investigations and to revisit our documented observations in order to determine the children's goals and the strategies they choose to attain those goals and to speculate about the theories that make the children's strategies reasonable. One strategy for revisiting video documentation that we have found most useful is the creation of a videative, a series of brief video clips embedded in explanatory text. The process of selecting video clips and composing the explanatory text contained in the videative enhances our understanding of the explorations and investigations we have observed (what), why our observations are relevant (so what), and how we can support and encourage the children's thinking in both depth and breadth (now what). To learn more about the videative as a powerful resource for educators, we invite you to go to http://www. videatives.com/videatives/demo

\section{References}

Coles, Robert. (1997). The moral intelligence of children. New York: Random House.

DeVries, Rheta. (1986). Children's conceptions of shadow phenomena. Genetic, Social, and General Psychology Monographs, 112(4), 479-530.

DeVries, Rheta, \& Fernie, David. (1990). Stages in children's play of tic-tac-toe. Journal of Research in Childhood Education, 4(2), 98-111.

Furth, Hans G. (1980). The world of grown-ups: Children's perceptions of society. New York: Elsevier.

Gelman, Rochel, \& Gallistel, C. R. (1978). The child's understanding of number. Cambridge, MA: Harvard University Press.

Girbau, Dolors. (2001). Children's referential communication failure: The ambiguity and abbreviation of message. Journal of Language and Social Psychology, 20(1-2), 81-89.
Glucksberg, Sam; Krauss, Robert M.; \& Weisberg, Robert. (1966). Referential communication in nursery school children: Method and some preliminary findings. Journal of Experimental Child Psychology, 3(4), 333-342.

Kalish, Charles W. (1996). Preschooler's understanding of germs as invisible mechanism. Cognitive Development, 11(1), 83-106. EJ 523 495.

Leslie, Alan M. (1987). Pretense and representation: The origins of "theory of mind." Psychological Review, 94(4), 412-426.

Springer, Ken. (1992). Children's awareness of the biological implications of kinship. Child Development, 63(4), 950-959. EJ 450564.

Wellman, Henry M., \& Gelman, Susan A. (1997). Knowledge acquisition in foundational domains. In Deanna Kuhn \& Robert S. Siegler (Eds.), Handbook of child psychology: Vol. 2. Cognition, perception, and language (pp. 523573). New York: Wiley. 


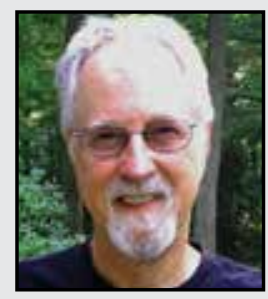

George Forman, professor emeritus at the University of Massachusetts, retired in 2003 to co-found Videatives, Inc. At Videatives, George designs digital video products and facilitates online courses on documentation. He has authored over seven books, three videotapes, and many research articles on early cognitive development through play and on how teachers can help children reflect on their own theories through drawing, video feedback, and conversations with adults. In the 1970s, he founded The School for Constructive Play, an experimental program for young children based on the learning theory of Jean Piaget. He is past president of the Jean Piaget Society and serves on numerous editorial boards.

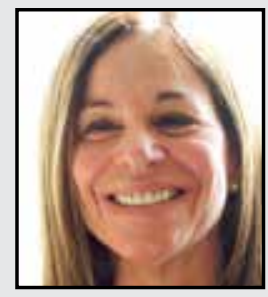

Ellen Hall is the founder and executive director of Boulder Journey School, a school for young children and families in Colorado and director of the Boulder Journey School Teacher Education Program, in partnership with University of Colorado Denver and the Colorado Department of Education. Ellen is a partner in Videatives, an online company providing resources for teacher education and professional development. Ellen travels internationally, sharing the work of Boulder Journey School with educators, leaders, and child advocates. Ellen serves on a number of boards and advisory committees, including Dimensions Educational Research Foundation, World Forum Foundation, and Hawkins Centers of Learning. Her research focuses on children's rights, with an emphasis on children's right to participation.

\section{LINK TO:}

http://www.videatives.com 